\section{A origem da Liga Brasileira de Higiene Mental e seu contexto histórico}

The origin of The Brazilian League of Mental Hygiene and its historical context

\begin{abstract}
André Augusto Anderson Seixas ${ }^{1}$, André Mota ${ }^{2}$, Monica L. Zilbreman ${ }^{3}$

${ }^{1}$ Pós-graduando, Departamento de Psiquiatria, Faculdade de Medicina, Universidade de São Paulo (USP), São Paulo, SP. ${ }^{2}$ Doutor. Professor de Pós-Graduação, Departamento de Medicina Preventiva, Faculdade de Medicina, USP. ${ }^{3}$ Doutora. Professora de Pós-Graduação, Departamento de Psiquiatria, Faculdade de Medicina, USP.

Os achados preliminares foram apresentados no XIV Congresso Mundial de Psiquiatria, realizado em setembro de 2008, em Praga, República Tcheca.
\end{abstract}

\section{Caros Editores,}

Em 1857, Morel introduziu o conceito de degeneração. A ideologia dominante era então o positivismo, caracterizado por ideais de modernidade, ordem, progresso e racionalidade. Os psiquiatras acreditavam não apenas que as doenças mentais tinham componentes biológicos e genéticos, mas também que tendiam a piorar à medida que eram transmitidas de geração para geração, causando a degeneração progressiva das árvores genealógicas e da população como um todo ${ }^{1}$. Para eles, a degeneração era mais que uma doença individual: tratava-se de uma ameaça social. A idéia de degeneração começou a estimular políticas sociais como esterilização, eutanásia e perseguição de indivíduos "degenerados"l.

A influência da higiene mental era especialmente importante. Esta acrescentava a noção de uma origem social da loucura à idéia já existente de que haveria uma base hereditária para a doença mental. Alcoolismo, miséria, ignorância ${ }^{2}$ e religiosidade ${ }^{3}$ extremas passaram a ser vistas como possíveis causas de loucura ${ }^{2,3}$. Enquanto isso, o Brasil passava por grandes mudanças e enfrentava sérios desafios sociais. A escravidão fora abolida em 1888, e a República fora declarada em 1889. Havia um fluxo considerável de imigrantes para o país. A urbanização descontrolada se intensificou, causando sérios problemas sociais e sanitários ${ }^{4}$. $\mathrm{Na}$ terceira década do século passado, um regime político denominado "Estado novo" entrou em vigor, armado de ideias antiliberais e atitudes repressivas. Uma nova constituição foi adotada, e alguns de seus artigos discutiam políticas de imigração que determinavam o número máximo de indivíduos de cada grupo étnico cuja entrada no país seria permitida. Nesse contexto, o movimento de higiene mental surgiu com a criação da Liga Brasileira de Higiene Mental. Fundada no Rio de Janeiro, em 1923, pelo psiquiatra Gustavo Riedel, a Liga tinha como objetivo primordial a melhoria na assistência aos doentes mentais, através da modernização do atendimento psiquiátrico ${ }^{5}$.

A Liga era uma entidade civil, reconhecida publicamente através de subsídios federais, e composta pelos mais importantes psiquiatras brasileiros. De 1923 a 1925 , a Liga seguiu a orientação de Riedel. A partir de 1926, influenciados pelo contexto político e pelo contato com ideias alemãs, francesas e norte-americanas, os diretores da Liga mudaram sua orientação, de modo que uma clara tentativa de "normalizar" a população tornou-se o principal objeto para os médicos em seus esforços para inibir os deficientes mentais 5 . Os princípios da eugenia e da higiene mental incentivavam psiquiatras que pretendiam colaborar para a criação de uma nação próspera, moderna e mais saudável ${ }^{4}$.

"O que queremos é gente de saúde mental e físico forte [.]. Eugenisemos o brasileiro, selecionemos os tipos arianos que nos procuram, escapemos à infiltração de nova dose de sangue mongólico [.]"4

Além de enfatizar a importância das ideias de degeneração no desenvolvimento da Liga Brasileira de Higiene Mental, gostaríamos de destacar o contexto histórico que cerca seu surgimento, a influência de conceitos eugênicos em nossa conceitualização de doença mental e a forma como isso serviu de modelo para nossas ideias atuais.

\section{Referências}

1. Shorter E. A History of Psychiatry: from the era of the Asylum to the age of Prozac. New York: John Wiley \& Sons; 1997.

2. Huertas R. Madness and degeneration, Part I. From 'fallen angel' to mentally ill. Hist Psychiatry. 1992;3(12):391-411.

3. Moreira-Almeida A, Neto FL, Koenig HG. Religiousness and mental health: a review. Rev Bras Psiquiatr. 2006;28(3):242-50.

4. Moreira-Almeida A, Silva de Almeida AA, Neto FL. History of "Spiritist madness" in Brazil. Hist Psychiatry. 2005;16(61 Pt 1):5-25.

5. Costa JF. História da Psiquiatria no Brasil. $5^{\mathrm{a}}$ ed. Rio de Janeiro: Garamond; 2007.

Correspondência:

André Augusto Anderson Seixas, Instituto de Psiquiatria, Faculdade de Medicina da Universidade de São Paulo, Rua Dr. Ovídio Pires de Campos, 785, CEP 05403-010, Cerqueira César, SP. Tel.: (11) 3069.6972. E-mail: aaaseixas@protoc.com.br.

Não há conflitos de interesse associados à publicação desta carta.

Copyright (C) Revista de Psiquiatria do Rio Grande do Sul - APRS 